\title{
Establishment of Music Emotion Model Based on Blockchain Network Environment
}

\author{
Ke Xu \\ Qingdao University of Technology, Qingdao 266033, China \\ Correspondence should be addressed to Ke Xu; xuke@qtech.edu.cn
}

Received 27 September 2020; Revised 27 October 2020; Accepted 24 November 2020; Published 11 December 2020

Academic Editor: Hongju Cheng

Copyright (C) $2020 \mathrm{Ke} \mathrm{Xu}$. This is an open access article distributed under the Creative Commons Attribution License, which permits unrestricted use, distribution, and reproduction in any medium, provided the original work is properly cited.

\begin{abstract}
With the innovation and development of network technology, people's various needs are gradually increasing. Among various multimedia, music has different characteristics from other forms of multimedia. Music can contain many human emotions, and humans can express some shallow and deep emotions through music. Therefore, the study of music emotion in the context of the Internet is an area where the public is relatively concerned. In the context of new media on the Internet, based on the current music emotion model, this paper establishes a different music emotion model from the past through clear research and analysis. From music characteristics, some relative vector quantities are extracted to build samples, and the samples are screened on the basis of network media technology to build a musical emotion model. The experimental simulation results show that the music emotion model based on the blockchain network environment established in this paper has high applicability and efficiency.
\end{abstract}

\section{Introduction}

The combination of network technology and music emotion is an important manifestation of the development of the times, and it is also the main direction of their common development $[1,2]$. The reason why music is created and highly praised is closely related to the emotions expressed by music. Nowadays, computer technology has become more and more developed. As a carrier of various emotions, music is presented around people in the form of multimedia and has a wide range of applications in many fields $[3,4]$. Some people suddenly realized that the application of computers to music can enhance people's understanding and control of music, and to a greater extent enhance the appeal and expressive power of music, and has extremely optimistic development prospects. Many high technologies have created a good environment for the development of music emotions [5].

The analysis of music emotion refers to the relatively complex process of generating automatic pattern recognition through computers and other technologies [6, 7]. Music itself is a special thing that can affect people's various emotions, life, and even ways of thinking. Music in network multimedia contains a large amount of information and data and is closely related to people's various emotions. Music has a strong presence in various forms of multimedia. The research of music emotion is of far-reaching significance to the current development of multimedia networks, network technology innovation, and the development of human-computer interaction $[8,9]$. Through network technology, the analysis of music emotion needs to be matched in the current emotion database, and the emotion is derived through the comparison of related data. Therefore, it is necessary to establish a musical emotion model. However, music emotion has the characteristics of great vagueness, and the information is relatively vague. In addition, there are no rules to follow, so it is difficult to analyze and process music emotions in general methods. There is basically no automatic music emotion recognition model that conforms to people's emotions. Therefore, analyzing music emotions is of great significance [10]. On this basis, combined with the new intermediary environment of the Internet, the establishment of a musical emotion model was studied. 


\section{The Development Status of Music Sentiment Analysis}

The combination of new online media and music is actually the result of the normal development of the times. At present, in the era of new media, network technology is ubiquitous, and computer music technology is needed in many fields $[11,12]$. High-tech equipment makes the development of computer music technology smoother under this current good network environment [13]. In fact, as early as a long time ago, some people used artificial intelligence technology to analyze music emotions, so as to realize automatic analysis and recognition of the emotions contained in music through this technology [14].

The research on music sentiment analysis in foreign countries is much earlier than in our country, and its development technology is becoming more and more mature and advanced. Japan has developed some products that can help music creation using its advanced artificial intelligence technology. When people input some lyrics and tones in the software product, the software will perform some analysis on the music emotion and find out the corresponding melody [15]. Therefore, many people believe that the discovery of this technology will greatly help music creation. However, my country's research in this area is relatively late. However, both the country and the people attach great importance to this research [16]. Many well-known key universities have also begun to participate in this research. Some research funds have been allocated for related research. In addition, our country also holds some important discussions and exchange meetings on a regular basis to further deepen the research on music sentiment analysis [17].

In this regard, many scholars are writing more and more academic papers. Music plays a pivotal role in people's lives and strongly affects people's growth and life. The research on music sentiment analysis has also become an area of increasing attention. As far as the research of music sentiment analysis is concerned, this research idea can not only be extended to other fields of application, but also can make the relatively vague artificial intelligence part more perfect [18]. At the same time, this research can enable better application of multimedia technology, thereby achieving greater development of multimedia technology in music creation and other aspects. In addition, the analysis of music emotion is actually a very meaningful research, which makes music unique in the process of the increasing development of today's network technology [19].

\section{Analysis of Current Musical Emotion Model}

The combination between computer technology and music is the inevitable result of the progress of times and the network multimedia development. Although the emotions contained in music have great indeterminacy and basically have no laws to follow, from the modern perspective, there are still some rules which can be explored $[20,21]$. The vibrations of sound waves and people's internal emotional activities actually have some correspondence, so the study can be conducted from this point. The first element to establish the musical emotion analysis model (shown as Figure 1) is to build musical emotion model, then to derive musical space [22].

There are mainly three types of musical space. The first one is musical emotion space which can lead out emotional annotation; the second one is musical feature space which can lead out feature extraction; the third sample space, based on the former two kinds of musical space, organically combines its emotional chain with feature flow together, so as to set up the foundation of musical emotion cognitive model $[23,24]$. Musical emotion analysis model is shown in Figure 1.

3.1. Heiner Emotion Model. In some current musical emotion models, Heiner emotion model is the most accepted by the public. This model generally adopts a circle to represent the inner emotional symbols (shown as Figure 2). Through an annulus, musical emotions are divided into different plates. Every plate has certain inheritance or close relationship with the two adjacent plates. It can be treated as a transformation process of emotions or a link of emotions' transition [25].

In this emotional annular model, it is only a conjecture that the musical emotions become to have some regularity. It is premised on people's certain emotional reflection situation that is relatively stable connected to some fixed elements in music. Then, the musical emotions represented in the annular model can be guaranteed to directly reflect people's inner emotions or show the rules and trends of this kind of reflection [26, 27]. For example, in the musician's Reflets dans idea, the elicitation process of musical emotions is from beginning lightness and cheerfulness to later enthusiasm and vitality $[28,29]$. So, it can verify that this model does have some existing significance.

$$
\begin{aligned}
& \text { Note }=\{\text { duration } ; \text { pitch } ; \text { intensity }\} \\
& \text { Note }=\{\text { duration } ; \text { pitch } ; \text { intensity }\}
\end{aligned}
$$

In music, the smallest unit is note which contains three features of pitch, intensity, and duration. Pitch represents the length of time between every note. Intensity is related to the frequency of vibrations. Duration refers to strength or volume when people listen to the sound of this note [30]. Therefore, note can be defined in this way. Heiner model of the music emotion model is shown in Figure 2.

The duration, pitch, and intensity successively refer to how long, how high, and how strong the note sounds [31]. So, the melody features of the music can be expressed in this way:

$$
\begin{array}{r}
\text { Melody }=(\text { note } 1, \text { note } 2, \text { note } 3 \text { notec }), \\
\text { Melody }=(\text { note1, note } 2, \text { note } \cdots \text { notec }) . \\
P\left(Y=\frac{c_{k}}{X=x}\right)=\frac{P\left(X=x / Y=c_{k}\right) P\left(Y=c_{k}\right)}{\sum_{k=1}^{K} P\left(X=x / Y=c_{k}\right) P\left(Y=c_{k}\right)}
\end{array}
$$

in which $k$ refers to the number of notes in a piece of music, i.e., the length of the melody.

In the application process, the actual need should be the standard to get the needed quantity from the features of the 


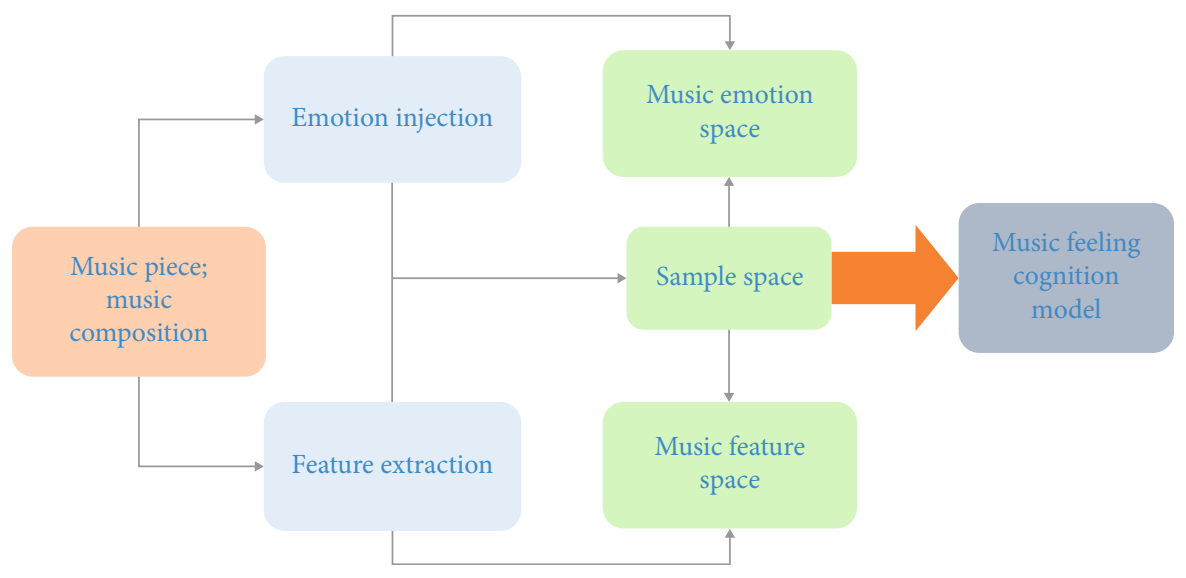

FIgURE 1: Musical emotion analysis model of the music emotion model.

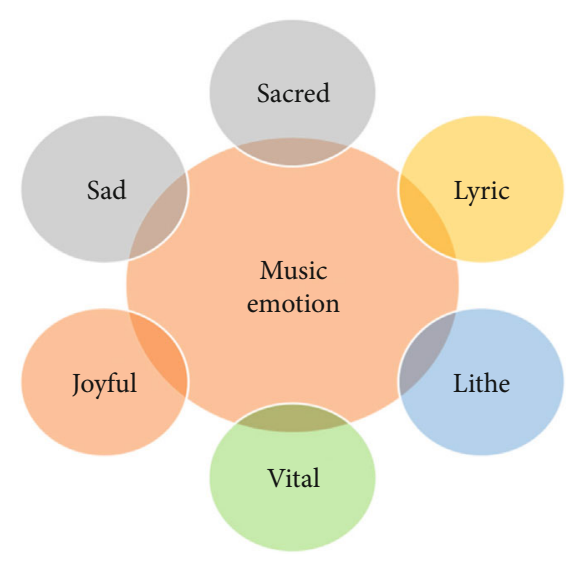

FIgURE 2: Heiner model of the music emotion model.

music to make study and analysis [32,33]. Also, according to the practical situation, some relevant data can be calculated for it, such as the degree of similarity and the degree of correlation, so as to meet the feature vectors of emotions.

$$
h_{\theta}(x)=\left[1+\exp \left(-\theta^{T} x\right)\right]^{-1} .
$$

Actually, this model is not an aggregation psychological model for emotions, but this model would analyze emotions through music or a series of artworks related to emotions.

$$
\mathrm{l}(\theta)=\prod_{i=1}^{n}\left[h_{\theta}(x)\right]^{y_{i}} \cdot\left[1-h_{\theta}(x)\right]^{1-y_{i}} .
$$

This is the premise of the analysis to suit some rules of emotions. Thus, the model is also commonly applied in other fields, such as art psychology, musical psychological study, and computer music study [34].

$$
y=f(x)=\operatorname{argmax} \frac{\prod_{j=1}^{n} P\left(X^{(j)}=x^{(j)} / Y=c_{k}\right) P\left(Y=c_{k}\right)}{\sum_{k=1}^{K}\left(Y=c_{k}\right) \prod_{j=1}^{n} P\left(X^{(j)}=x^{(j)} / Y=c_{k}\right)} .
$$

3.2. Thayer Emotion Model. This model is structured through a sort of two dimensions, energy, and pressure, to make analysis on emotions. In terms of energy dimension, the lowest coordinate point is contentment and gradually rises to an exuberance level [35]. In this process, any level in it can embody a kind of emotion. The level embodiment of this dimension can express at many levels. And in the pressure dimension, it mainly embodies the emotional performance from happiness to anxiety in varying degrees [36]. Thayer Model of the music emotion model is shown in Figure 3.

People's inner emotional features can be represented by adopting Thayer model through different levels' embodiment of the two dimensions. Thayer model is a relatively continuous musical emotion expression model, to present a kind of continuous psychological emotions. Based on this continuous feature, it will perform naturally while different emotions are carrying on, rather than transforming ponderously and suddenly. However, one shortcoming of Thayer model lies in that there is not too much space for emotional activities. Two dimensions absolutely cannot confirm the abundant emotional expression. After all people's emotions are influenced by multiple factors. This is also the reason why the model is rarely applied.

\section{Key Melody Recognition of Musical Emotions}

Melody is the core of a piece of music, which was conducted by a series of relevant notes through varying rhythms and tones with purposes. In a piece of music, the leading melody represents the foundational emotions what this piece of music expects to express. However, for computers, those emotions cannot be directly obtained, but need to be embodied via some features in the music. Thus, in order to analyze musical emotions, it is necessary to analyze and study the features of the leading melody of the music.

4.1. Format Selection of Audio Files. The construction of musical melody features can analyze music on inner musical emotions more deeply. Then, the first thing to be sure is which format of music can become the main data sources to extract musical melodies. From current situation, it can be seen that there are many file formats of computer music, 


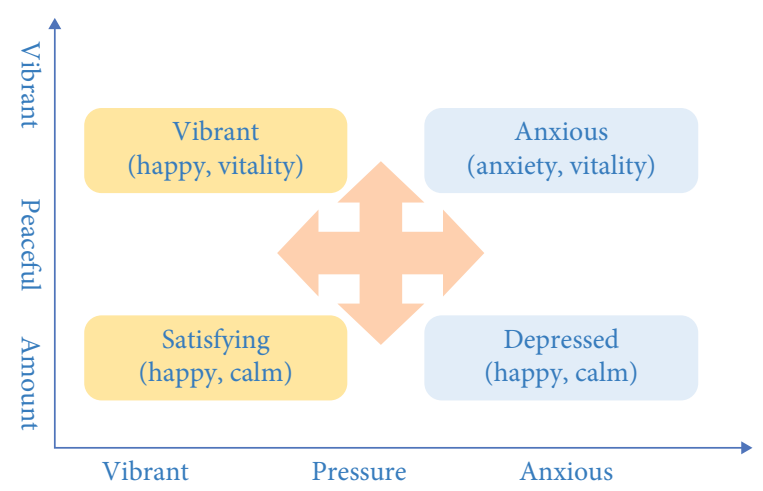

Figure 3: Thayer model of the music emotion model.

and each format has different features. Generally speaking, the formats of computer music can be divided into three categories as below. Sound files are also called as audio files which refer to the files obtained by directly simulating the waveform of practical sound through computer sampling. This is a kind of reflection to practical sound. And this will cause the files occupy a lot of storage space. Computer music file response efficiency at different times is shown in Figure 4.

What MIDI files record is a kind of instruction sequence during instrumental performance, excluding the records of actual musical data. This kind of files often records the instruments and contents in different tracks. The files clearly record which instrument performs what notes at that period of time. So this sort of files does not take up large space. Also, it is very convenient to extract the musical features. The music files of this format can directly be extracted in detail. Module files have common characteristics of the other two kinds of files, recording both actual sound and the instruction sequence during instrumental performance. However, there are many coding schemes of this kind of files, so there are also many types of formats. If people extract musical features to this type of files, they should make decoder processing for different formats, and the operation process will be a little complicated. In the comparison of the three kinds of musical files above, it is not difficult to see that choosing the musical file of MIDI will be more convenient to extract the features of musical melodies.

\section{Establishment of Musical Emotion Model Based on Network New Media Environment}

5.1. Extraction of Features. Before the establishment of a model, it is necessary to obtain some data. In the establishment of musical emotion model, the data in the aspects of pitch, duration, and timbre in the music can be selected. The value of pitch depends on the frequency of things' vibrations. The pitch is proportional to the vibration frequency. The higher the vibration frequency, the higher the pitch. In the music of MIDI type, the high and low sounds are mainly under the effect of musical value, generally from 0.0 to 127.0. If $f$ is used to represent the pitch in music as a function, the musical emotions can mainly be analyzed from the master track. It is assumed that current music has $m$ tracks, and then relevant pitches are, respectively, extracted in the $m$ tracks.
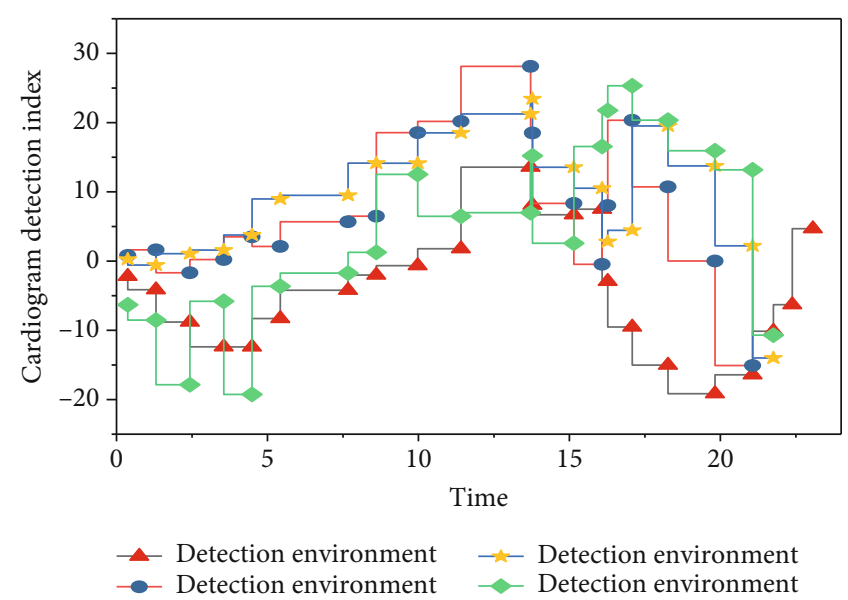

FIgURE 4: Computer music file response efficiency at different times.

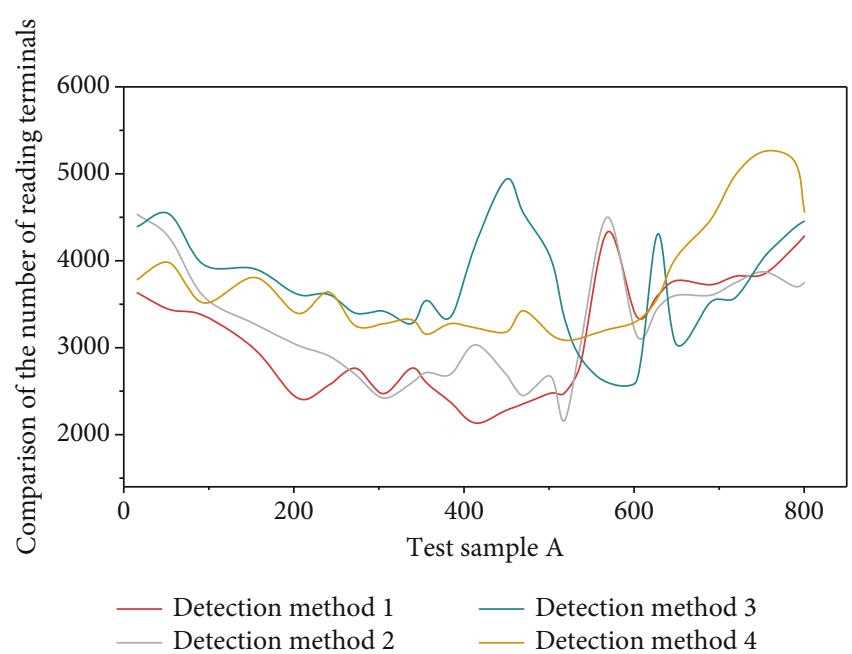

FIgURE 5: The characteristics of the duration vector of notes in different environments.

The feature vector $x j$ of the pitch in the music will be determined according to the special attributes of the master track. It is assumed that the whole musical emotional type is $n$, and $n$ is greater than or equal to one. Then, the performance characteristics of musical emotions under the influence of the vector of pitch will be $P i(x f)$, where $i$ is positive integer. So, the relationship between the emotions represented by the music and its pitch can be expressed as follows:

$$
f\left(x_{f}\right)=\operatorname{Max}\left(p_{i}\right) .
$$

In musical emotions, the pitch has its great influence. But the specific relationship between the two should be further confirmed in light of recognition. Duration is the length of time when some note is sounded in the music. In music, duration opening represents the note begins to make a sound, and duration closing means the note ends to make a sound. The function $g$ refers to the duration feature in the music in study. Generally speaking, longer duration in music may mean that the piece of music has more dolorous 
TABLE 1: Music statistics.

\begin{tabular}{lcc}
\hline Musical type & Number & Typical pieces of music \\
\hline Film type & 50 & The Legend of the Condor Heroes, To the sky kingdom, etc. \\
Popular type & 53 & Outside the Light Year, The Brightest Star in the Night Sky, etc. \\
Classical type & 45 & Pink Memories, The Moon Represents My Heart, etc. \\
Religious type & 18 & The Great Compassion Mantra, The holy Epithet of Name Bodhisattva, etc. \\
Chinese type & 34 & Ninjago - Meditate on the Past at Red Cliff, Gold-Woven Dress, etc. \\
\hline
\end{tabular}

elements. The extraction of the vector of duration can carry out according to the continuous time of notes.

$$
g\left(x_{g}\right)=\left\{\begin{array}{l}
\text { long, } x_{g} \geq x_{\text {switch }} \\
\text { short, } x_{g}<x_{\text {switch }}
\end{array} .\right.
$$

$x$ represents the time of the duration from duration opening to duration closing. Switch represents the threshold value of the duration. In light of this formula, the duration time of the music can be confirmed, so as to confirm the duration vector characteristics of the notes in the music. The characteristics of the duration vector of notes in different environments are shown in Figure 5.

Different instruments can present different sound waves. Timbre is affected by harmonic waves, and the different construction situation of harmonic waves will make timbre change with it. For example, the timbre of piano is very elegant and steady, which gives people a relaxed feeling. But the timbre of erhu is a little harsh, which is easy to make people feel sorrowful. So, different instruments are labeled to define 120 kinds of timbre, so as to extract the timbre features. Timbres are corresponded to emotions, to divide 120 kinds of timbres into K types. The formula $h$ represents the extraction of timbre vectors in current music.

$$
h_{x_{i}}=\left\{\begin{array}{cc}
1 & x_{i} \in C_{1} \\
2 & X_{i} \in C_{2} \\
\vdots & \\
M & X_{i} \in C_{M}
\end{array} .\right.
$$

In various audio tracks of music, even the timbre of the same audio track may immediately change as long as the time changes. So, the extraction of timbre feature music should adopt a kind of dynamic method. Through the three basic elements, in terms of musical space features and vector model of emotion features, a dimension space with six dimensions can be produced. In this dimensional space, the distribution of elements should be average. It should be known that in massive pieces of music, the intensity distribution of a piece of music is relatively average. There is no significant difference in the features in some aspects. For some places without obvious features, the extraction does not need to be conducted.

Range: range $=1 / n \sum_{i-1}^{n}$ pitch $_{i}$.

Intensity: intensity $=1 / n \sum_{i-1}^{n}$ intensity $_{j}$.

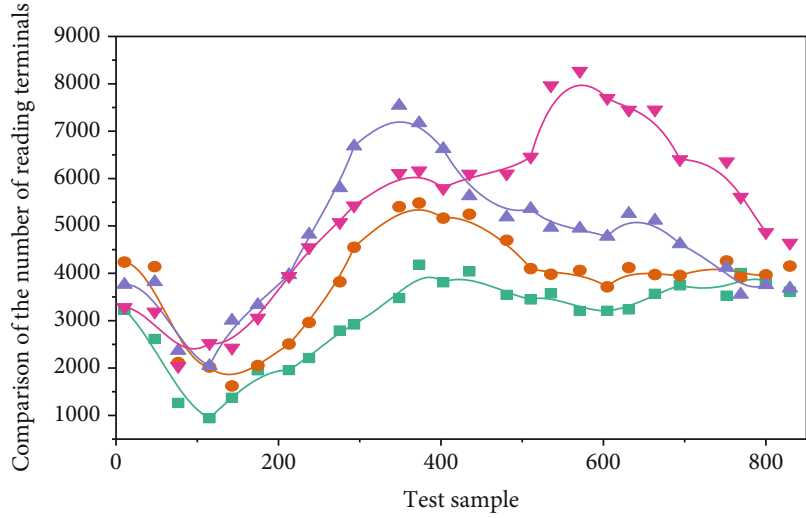

- Auxiliary test standards a $\quad \longrightarrow$ Auxiliary test standards c - Auxiliary test standards b $\longrightarrow$ Auxiliary test standards d

Figure 6: Music sentiment classification test results.

Melody direction: $\quad$ Dir_Pit $=\sum_{i-1}^{n}$ intensity $_{i} \cdot$ duration $_{i} /$ duration_music - duration ${ }_{n}$.

Pitch stability: Sta_pitch $=\sqrt{1 / n \sum_{n-1}^{n}(\text { pitch }- \text { range })^{2}}$.

$$
\begin{aligned}
& \text { Interval stability: } \\
& \sqrt{1 / n \sum_{i-1}^{n}\left(\mid \text { interval }_{i}|-| \overline{\text { invertal }} \mid\right)^{2}} . \\
& \text { Interval span: } \operatorname{Span}-\operatorname{Int}=1 / n-1 \sum_{i-1}^{n-1} \mid \text { interval }_{i} \mid .
\end{aligned}
$$

5.2. Establishment of Samples. According to some relatively professional music websites, music libraries, and other resource approaches, some professional people in music colleges establish the samples of music to classify the emotions expressed in various kinds of music. 200 pieces of music are handpicked, including 50 pieces of sentimental music, 53 pieces of passionate music, 52 pieces of classical music, and 45 pieces of inspirational music. The basic classification is shown in Table 1.

From the emotion-classified pieces of music above, 20 samples are randomly selected as the data to test, and the others are training data. It is found that the obtained network classification presents scarcely ideal results. As for the establishment of musical samples, some deviations will be produced in testing period because of many elements. So, the samples cannot be directly applied; otherwise, they will influence the final results. So, some screenings should be conducted for the samples. Music sentiment classification test results are shown in Figure 6.

The network's input level can set six-dimension vectors of musical emotion features. The six dimensions are, 
respectively, range, intensity, melody direction, pitch stability, interval stability, and interval span. The input node number is set as 6, and the output is musical emotions. According to current Heiner model, music is divided into eight different types. The output note is $3(\log 82=3)$.

According to the Kolmogorov theory of $n 1=2 n+1(n 1$ represents the number of hidden layer nodes, and $n$ represents the number of input nodes), $n 1=13$ can be drawn. So, the final established nerve network construction is $6 *$ $13 * 3$, where 6 notes refer input level, 13 notes represent the hidden level, and 3 notes refer to output level. On this basis, the hidden level and output level can both be calculated by Sigmoid formula $f(x)=1 / 1+e^{x}$. In this way, the ultimate output value can be ensured to show between zero and one. In the whole network system, the biggest cycle index is set at 3000 , with the deviation about 0.003 . The training formula is a training formula. The learning formula adopts a gradient descent momentum learning formula. The performance function takes a mean square error performance function.

\section{Conclusion}

The knowledge and technology applied in the analysis of computer musical emotion analysis are extremely extensive. And the neural network modeling needs to be understood to some extent while conducting it. Musical emotion analysis is the important understanding of multimedia contents, as well as the important member in artificial intelligence, applied in various fields. With the significant development of today's network new media, musical emotion analysis also constantly integrates with it, to become a vital direction of network multimedia development at present. In this paper, the establishment of musical emotion model builds a good platform for the extraction of more the same emotional music, for the purpose of set up a good foundation for the application in practice. In addition, how to master more advanced technology more deeply, to develop more studies with practical significance, and make further innovation, is the current and future direction and objective of common effects.

\section{Data Availability}

All author information is available from the author.

\section{Conflicts of Interest}

The author declares that there is no conflict of interest regarding the publication of this paper.

\section{References}

[1] A. Järvinen, R. Ng, D. Crivelli et al., "Social functioning and autonomic nervous system sensitivity across vocal and musical emotion in Williams syndrome and autism spectrum disorder," Developmental Psychobiology, vol. 58, no. 1, pp. 17-26, 2016.

[2] C. Jiang, F. Liu, and P. C. M. Wong, "Sensitivity to musical emotion is influenced by tonal structure in congenital amusia," Scientific Reports, vol. 7, no. 1, p. 7624, 2017.
[3] C. Liegeois-Chauvel, "Musical emotion memory, evidence of lateralized anteromedial temporal structures," International Journal of Psychophysiology, vol. 100, no. 108, p. 31, 2016.

[4] D. Raynaud, S. Gessner, and B. Mota, “Andalò di negro's de compositione astrolabii: a critical edition with english translation and notes," Archive for History of Exact Sciences, vol. 73, no. 6, pp. 551-617, 2019.

[5] M. Forcada, F. J. Ragep, and T. Mimura, "On astronomia: an arabic critical edition and english translation of epistle 3," Journal for the History of Astronomy, vol. 47, Part 3, pp. 346347, 2016.

[6] A. Aljanaki, F. Wiering, and R. C. Veltkamp, "Studying emotion induced by music through a crowdsourcing game," Information Processing \& Management, vol. 52, no. 1, pp. 115-128, 2016.

[7] A. Shook and V. Marian, "The influence of native-language tones on lexical access in the second language," Journal of the Acoustical Society of America, vol. 139, no. 6, p. 3102, 2016.

[8] S. Panwar, P. Rad, K. K. R. Choo, and M. Roopaei, “Are you emotional or depressed? Learning about your emotional state from your music using machine learning," Journal of Supercomputing, vol. 75, no. 6, pp. 2986-3009, 2019.

[9] S. Hans-Eckhardt, "Music-evoked emotions-current studies," Frontiers in Neuroence, vol. 11, p. 600, 2017.

[10] W. C. Wang, "The effect of adaptive music playing system on emotion regulation," Journal of the Acoustical Society of America, vol. 140, no. 4, pp. 3380-3380, 2016.

[11] I. Dufour and G. Tzanetakis, "Using circular models to improve music emotion recognition," IEEE Transactions on Affective Computing, vol. 4, no. 16, pp. 1-1, 2018.

[12] N. Vannson, H. Innes-Brown, and J. Marozeau, "Dichotic listening can improve perceived clarity of music in cochlear implant users," Trends in Hearing, vol. 19, 2015.

[13] R. Xue, S. Huang, X. Luo, D. Jiang, and R. Y. Da Xu, "Semantic emotion-topic model in social media environment," Journal of Web Engineering, vol. 17, no. 1-2, pp. 73-92, 2018.

[14] R. Qin, C. Zhou, H. Zhu, M. Shi, F. Chao, and N. Li, "A musicdriven dance system of humanoid robots," International Journal of Humanoid Robotics, vol. 15, no. 5, p. 1850023, 2018.

[15] J. J. Deng and C. H. C. Leung, "Dynamic time warping for music retrieval using time series modeling of musical emotions," IEEE transactions on affective computing, vol. 6, no. 2, pp. 137-151, 2015.

[16] B. Bogert, T. Numminen-Kontti, B. Gold et al., "Hidden sources of joy, fear, and sadness: explicit versus implicit neural processing of musical emotions," Neuropsychologia, vol. 89, pp. 393-402, 2016.

[17] C. G. Tsai and C. P. Chen, "Musical tension over time: listeners' physiological responses to the 'retransition' in classical sonata form," Journal of New Music Research, vol. 44, no. 3, pp. 271-286, 2015.

[18] X. Liu and H. Zhao, "Hierarchical feature extraction based on discriminant analysis," Applied Intelligence, vol. 49, no. 7, pp. 2780-2792, 2018.

[19] H. I. Ozercan, A. M. Ileri, E. Ayday, and C. Alkan, "Realizing the potential of blockchain technologies in genomics," Genome Research, vol. 28, no. 9, pp. 1255-1263, 2018.

[20] Z. Yinghui, R. H. Deng, L. Ximeng, and Z. Dong, "Blockchain based efficient and robust fair payment for outsourcing services in cloud computing," Information Sciences, vol. 462, pp. $262-277,2018$. 
[21] Y. Liu, M. Ma, X. Liu, N. Xiong, A. Liu, and Y. Zhu, "Design and analysis of probing route to defense sink-hole attacks for Internet of Things security," IEEE Transactions on Network Science and Engineering, vol. 7, no. 1, pp. 356-372, 2018.

[22] K. Gammon, "Experimenting with blockchain: can one technology boost both data integrity and patients' pocketbooks?," Nature Medicine, vol. 24, no. 4, pp. 378-381, 2018.

[23] V. Sharma, I. You, F. Palmieri, D. N. K. Jayakody, and J. Li, "Secure and energy-efficient handover in fog networks using blockchain-based DMM," IEEE Communications Magazine, vol. 56, no. 5, pp. 22-31, 2018.

[24] E. Funk, J. Riddell, F. Ankel, and D. Cabrera, "Blockchain technology: a data framework to improve validity, trust, and accountability of information exchange in health professions education," Academic Medicine, vol. 93, no. 12, pp. 17911794, 2018.

[25] L. Li, J. Liu, L. Cheng et al., "Creditcoin: a privacy-preserving blockchain-based incentive announcement network for communications of smart vehicles," IEEE Transactions on Intelligent Transportation Systems, vol. 19, no. 7, pp. 2204-2220, 2018.

[26] W. Pan and C. Chai, "Structure-aware Mashup service clustering for cloud-based Internet of Things using genetic algorithm based clustering algorithm," Future Generation Computer Systems, vol. 87, pp. 267-277, 2018.

[27] G. Yang, Q. Yang, and H. Jin, "A novel trust recommendation model for mobile social network based on user motivation," Electronic Commerce Research, vol. 4, no. 8, pp. 56-59, 2019.

[28] K. N. Khaqqi, J. J. Sikorski, K. Hadinoto, and M. Kraft, "Incorporating seller/buyer reputation-based system in blockchainenabled emission trading application," Applied energy, vol. 209, pp. 8-19, 2018.

[29] J. M. Roman-Belmonte, H. De la Corte-Rodriguez, and E. C. Rodriguez-Merchan, "How blockchain technology can change medicine," Postgraduate Medicine, vol. 130, no. 4, pp. 420427, 2018.

[30] S. S. Ahmad, S. Khan, and M. A. Kamal, "What is blockchain technology and its significance in the current healthcare system? A brief insight," Current Pharmaceutical Design, vol. 25, no. 12, pp. 1402-1408, 2019.

[31] A. Pavlidis, M. Dimolianis, K. Giotis, L. Anagnostou, and V. Maglaris, "Orchestrating DDoS mitigation via blockchainbased network provider collaborations," The Knowledge Engineering Review, p. 35, 2020.

[32] M. Shabani, "Blockchain-based platforms for genomic data sharing: a de-centralized approach in response to the governance problems?," Journal of the American Medical Informatics Association, vol. 26, no. 1, pp. 76-80, 2019.

[33] Y. Liu, M. Ma, X. Liu, N. Xiong, A. Liu, and Y. Zhu, "Design and analysis of probing route to defense sink-hole attacks for Internet of Things security," IEEE Transactions on Network Science and Engineering, vol. 7, no. 1, pp. 356-372, 2020.

[34] F. Long, N. Xiong, A. V. Vasilakos, L. T. Yang, and F. Sun, “A sustainable heuristic QoS routing algorithm for pervasive multi-layered satellite wireless networks," Wireless Networks, vol. 16, no. 6, pp. 1657-1673, 2010.

[35] Y. Zhou, D. Zhang, and N. Xiong, "Post-cloud computing paradigms: a survey and comparison," Tsinghua Science and Technology, vol. 22, no. 6, pp. 714-732, 2017.

[36] W. Pan and C. Chai, "Measuring software stability based on complex networks in software," Cluster Computing, vol. 22, no. S2, pp. 2589-S2598, 2019. 